\title{
O Programa Bairrinho nas favelas de Praia da Rosa e Sapucaia $(\mathrm{RJ})$
}

\author{
MARIA DE FÁTIMA CABRAL MARQUES GOMES \\ ¿ LENISE LIMA FER NANDES
}

\section{Introdução}

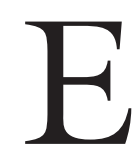

STE TRABALHO discute os primeiros resultados do follow-up do processo de urbanização das favelas Praia da Rosa e Sapucaia, na Ilha do Governador, pela Prefeitura Municipal da Cidade do Rio de Janeiro, por meio do Programa Bairrinho, entre 1996 e 1998. Tal investigação compõe a pesquisa comparativa "Social Exclusion, Territories and Urban Policies: a comparison between India and Brazil" (Setup), coordenada pela Ehess/Centre d'Etudes de l'Inde et de l'Asie du Sud, em Paris. No Brasil, os estudos estão sendo realizados por pesquisadores da USP, em São Paulo, e do Núcleo de Pesquisa e Extensão Favela e Cidadania (Faci/UFRJ), no Rio de Janeiro. O estudo teórico-empírico desenvolvido pelo Faci visa analisar o impacto da urbanização dessas favelas nos processos de inclusão/exclusão social de seus moradores. Com esse objetivo organizamos a pesquisa em duas etapas. A primeira, ocorrida em 2008 e de natureza qualitativa, realizou entrevistas semiestruturadas com atores-chave externos e internos às favelas, diretamente envolvidos nessa intervenção. A segunda, já em curso, atualizará o banco de dados construído com base no censo de 1996, que precedeu a urbanização daquelas favelas, permitindo a análise mais aguçada das alterações/permanências das condições de vida da população dessas favelas no decorrer dos últimos 13 anos.

Articulada à perspectiva da pesquisa Setup, nossa óptica sobre o fenômeno de inclusão/exclusão ${ }^{1}$ urbana o analisa como heterogêneo, a partir de dois aspectos centrais. Primeiro, articula as dimensões econômica, histórica e simbólica que o compõem na dinâmica capitalista. Segundo, considera sua configuração a partir de distintos processos que o tornam complexo, que interagem de forma imbricada e dão concretude à totalidade de sua expressão. Tomamos como referência as intervenções em favelas empreendidas a partir de 1990, quando a prefeitura carioca reformulou a política para essas áreas. Privilegiamos a concepção holística e histórica do planejamento urbano, reconhecendo a face política desse instrumento de gestão e entendendo seus destinatários como sujeitos, e não meros objetos na intervenção. 
A primeira parte do artigo apresenta nossa posição no debate teórico brasileiro sobre exclusão/inclusão e situa o Programa Bairrinho, implantado nessas favelas, no conjunto da política urbana carioca. A segunda examina discursos e práticas acerca dos desdobramentos dessa ação. Finalmente, tecemos algumas conclusões preliminares com base neste estudo.

\section{Inclusão e exclusão - conceito, expressões empíricas e proposta de enfretamento através do Programa Bairrinho}

\section{Breves considerações sobve o uso dos termos inclusão e exclusão}

Apesar do amplo uso da expressão exclusão social, a maioria dos autores retomados a associa a problemas produzidos pelo aprofundamento histórico das desigualdades sociais nas sociedades capitalistas. Conforme ressaltam Guimarães et al. (2002), situações da falta de proteção social, trabalho remunerado e/ou recursos, vistas como situações de pobreza, são manifestações empíricas relevantes para refinar esse conceito. Há abordagens que valorizam a dimensão sociocultural do fenômeno (Xiberras, 1993; Elias \& Scotson, 2000), reconhecem processos distintos ligados ao fenômeno e alertam que eles podem produzir situações de ruptura na relação indivíduo/sociedade, a depender das realidades onde ocorrem (Wacquant, 2000). Porém, a diversidade semântica do termo não é obstáculo ao debate, que tem avançado e indicado a possibilidade de consenso sobre algumas ideias, tais como as do dinamismo e da multidimensionalidade como características inerentes a situações que expressam o fenômeno.

No Brasil, o debate sobre exclusão ganhou relevância no contexto pósditadura militar, com o aumento da visibilidade dos sujeitos coletivos na esfera pública e com o fortalecimento sociedade civil. Identificada na crítica à teoria da marginalidade social e ao desenvolvimento econômico brasileiro (Cardoso \& Falleto, 1970; Oliveira, 1972), a exclusão social foi depois reconhecida como característica estrutural dessa sociedade mediante análise de diversos processos sociais (Buarque, 1991, 1993; Oliveira, 1997; Veras, 1999).

Segundo Martins (1997), na sociedade capitalista não existe exclusão como condição definitiva e irreversível, mas como contradição. Admite ser pertinente discutir processos sociais, econômicos e políticos excludentes, entendendo a análise de suas expressões concretas como níveis de desumanização. Nesse sentido, o autor considera impertinente a utilização da categoria exclusão social como categoria analítica, porque a vê como: a) um rótulo abstrato que não corresponde, de fato, a nenhum sujeito social; b) uma impressão superficial daqueles que se consideram aderidos ao sistema, no plano econômico e de seus valores sociais correspondentes; c) como categoria que ignora a dinamicidade do mundo, assim como a relevância das lutas contemporâneas, para alteração, inclusive, dos processos de exclusão e de integração. Martins prefere denominar tais situações como formas degradadas de inclusão, ressaltando que as análises sobre essas situações deveriam abranger as privações de ordem material, bem como as de natureza simbólica e social. 
Diante da heterogeneidade que perpassa a aplicação do termo, consideramos o fenômeno de exclusão social a partir de suas distintas dimensões e escalas, bem como dos processos de vida a ele relacionados. ${ }^{2}$ Nesse sentido, propomos uma articulação entre os enfoques de Martins (1997) e de Oliveira (2003). Trataremos as condições analisadas, então, como expressões simultâneas de situações de inclusão/exclusão, sempre relativas. Compartilhamos a visão de que a expressão das desigualdades sociais geradas pela distribuição desigual de riqueza e renda se estende às formas de ocupação e uso da cidade (Gomes et al., 2006), e que sua completa reversão é inalcançável nos limites do capitalismo. Por isso, consideramos premente a sistemática análise dos programas que propõem atenuar os impactos dessas condições sobre os segmentos da população a que se destinam, sobretudo para que os mecanismos que as produzem não sejam reiterados sob o falso véu das grandes alternativas.

\section{O Programa Bairrinbo como alternativa à inclusão de favelas}

O processo de urbanização brasileiro retrata as determinações do modelo econômico excludente implantado no país. $\mathrm{O}$ acentuado crescimento urbanoindustrial, entre 1930 e 1980, realizou-se mediante um processo de concentração de riqueza, excluindo a grande maioria da população brasileira (Piquet, 2000; Gomes, 2002). Historicamente, tal crescimento tem produzido cidades desiguais, onde se observa a sistemática negação do direito ao acesso a bens e serviços urbanos para amplas parcelas da sociedade brasileira. Para os segmentos da população cuja pobreza ultrapassa a dimensão econômica, a negação do direito à cidade assume também dimensões simbólicas mediante o não reconhecimento da legitimidade das formas distintas de produção e uso do espaço urbano que ocupam (Fernandes, 2003) e a reduzida interferência nas diretrizes do planejamento urbano e das questões públicas em geral.

Nas grandes cidades, a favela constitui-se em solução de moradia mais recorrente para populações pobres. Dados de 2008 do Instituto Pereira Passos (IPP) revelam existir 968 favelas no Rio de Janeiro, consideradas heterogêneas. ${ }^{3}$ Essas mantêm intensa articulação na dinâmica urbana, pela proximidade física entre as áreas nobres e populares, e pela circulação entre esses espaços e as redes de convivência entre eles. ${ }^{4}$ Porém, alguns autores abordam as favelas como lugares homogêneos da pobreza urbana, como espaços segregados da cidade. Essa visão é reforçada pela imagem de violência ligada à intensificação do tráfico de drogas nesses locais. Porém, a análise dessa dinâmica nas favelas e do processo de urbanização nos permitiu repensar a questão da cidade partida. Essa concepção simplifica a abordagem da cidade e a toma como um mero reflexo de uma sociedade de extremos em que o rico é cada vez mais rico e o pobre cada vez mais pobre (Laplatine \& Pordeus Júnior, 2001).

Com a descentralização político-administrativa indicada na Constituição de 1988, a política urbana na cidade do Rio de Janeiro buscou enfrentar desafios indicados nesse debate, visando à inclusão e integração social de áreas e segmen- 
tos populacionais distintos na dinâmica do atual desenvolvimento urbano. $\mathrm{O}$ município assumiu, então, papel importante com relação às políticas sociais e de habitação, em especial. Assim, foi criada a Secretaria Municipal de Habitação $(\mathrm{SMH})$, com programas de habitação diferenciados: Grandes Favelas, FavelaBairro, Bairrinho, Morar Legal, Morar Carioca, Morar sem Risco e Morando no Centro. ${ }^{5}$ A garantia do direito de propriedade é prevista via transformação do espaço ocupado pelas favelas em Áreas de Especial Interesse Social (Aeis).

A viabilidade econômica do Programa Favela-Bairro no Rio foi conferida pelo financiamento do BID. Assim, sua visibilidade foi amplamente favorecida, contribuindo para transformar o programa em "modelo" de intervenção para urbanização de favelas, inspirando iniciativas similares dentro e fora do país. ${ }^{6} \mathrm{O}$ Programa Bairrinho, destinado às favelas com 100 a 500 moradores, tem sido realizado nos moldes do Programa Favela-Bairro. Ambos foram previstos no âmbito de planos distintos que se sobrepõem na gestão da cidade: o Plano Diretor da Cidade do Rio de Janeiro (1992) e os Planos Estratégicos I e II (1996 e 2004). Em razão disso, a implementação desses programas reproduz o paradoxo de combinar orientações expressas no Plano Diretor, no sentido de garantir a universalização do direito à cidade, com aquelas que privilegiam a inserção da cidade no quadro da competitividade urbana, conforme as diretrizes do Plano Estratégico (Fernandes, 2003; Gomes, 2006).

A seguir, analisamos o modo como esse paradoxo e as injunções dele decorrentes materializam-se no cotidiano da população contemplada nessas intervenções, impondo limites aos objetivos de democratização da cidade. Entretanto, para compreender a dinâmica de algumas situações nas relações sociais e nas condições de vida dos moradores das favelas de Praia da Rosa e Sapucaia, nos últimos 13 anos, faz-se necessário recuperar as condições que marcaram a execução do Programa Bairrinho nessas áreas. Apenas comparando os dados obtidos em 1996 com os que hoje levantamos nas favelas é que podemos compreender o movimento dos processos de inclusão/exclusão social nessas áreas. Ressaltamos, porém, que não atribuímos a esse programa ou a qualquer outra intervenção urbanística por si só a capacidade de interromper ou acirrar tais processos. Ao contrário, eles são por nós enfocados tendo em conta a dinâmica atual do capitalismo, no contexto da globalização da economia.

\section{Impactos do Programa Bairrinho: discursos e práticas}

\section{Breve resgate da intervenção analisada}

Praia da Rosa e Sapucaia são favelas situadas em área contígua, às margens da Baía de Guanabara, no bairro do Tauá, que integra a Ilha do Governador. ${ }^{7}$ Encontram-se a cerca de 20 quilômetros do centro urbano do Rio de Janeiro, contam com opções de comércio no seu entorno e avizinham-se a outras duas grandes favelas - Morro do Dendê e Querosene da Ilha.

As obras de caráter físico e urbanístico realizadas nessas favelas ocorreram entre meados de 1996 e o início de 1998, beneficiando cerca de 3.300 morado- 
res. A prefeitura carioca considerou as situações fundiária e imobiliária encontradas no local, bem como as melhorias realizadas pelos moradores, promovendo uma intervenção do tipo upgrading, conforme as recomendações do Habitat II (Gomes, 2006). Embora as diretrizes do Programa Bairrinho previssem uma intervenção mínima nos domicílios, nessas favelas, por pressão dos moradores, a prefeitura construiu embriões em substituição às 149 palafitas removidas.

A postura desses moradores ante a urbanização já se mostrava distinta da encontrada nas demais favelas da cidade, por condições históricas bastante peculiares. Em razão de antigas ameaças de remoção, desde 1986 os residentes e suas entidades representativas demandavam a urbanização da área ao poder público. Àquela época, tal mobilização foi fortalecida pela assessoria da Escola de Serviço Social da UFRJ, por meio do trabalho de pesquisa e extensão universitária realizado pelo Faci que, para respaldar a luta, realizou um levantamento de modo a caracterizar os moradores e suas condições de vida. Criou-se uma base de informação para dar suporte à elaboração de um projeto de urbanização que contemplasse interesses e necessidades da população local. Com apoio de técnicos da Coppe/UFRJ e em conjunto com a população, a proposta dos moradores foi registrada no dossiê "Queremos urbanização".

Em 1996, a Secretaria Municipal de Habitação (SMH) do Rio de Janeiro decidiu atender parte das reivindicações da população, incorporando-as ao Projeto Bairrinho em Praia da Rosa e Sapucaia. Tal execução contou novamente com o trabalho de assessoria do Núcleo Faci às entidades organizativas locais, aos moradores de forma ampla e à própria prefeitura, já que o Núcleo encampou o trabalho social que daria suporte à urbanização, em convênio cooperativo com a SMH. Foi realizado novo censo visando atualizar a caracterização física, econômica e social das favelas. A dinâmica de participação social nesse processo envolveu discussões sistemáticas das etapas e do detalhamento da ação junto aos moradores, com contribuição de representantes de movimentos populares locais (Federações de Favelas - FAF-Rio, Movimento Os Verdes e ativistas em prol dos manguezais), ativistas do Partido dos Trabalhadores (PT), representantes da Cedae, Comlurb e outras instituições, contrapondo-se à maioria das experiências de urbanização em que a participação é marginal e instrumentalizada (Gomes \& Fernandes, 2007). A ativa participação popular reverteu pontos do projeto contrários às expectativas dos moradores e favoreceu a negociação de interesses em conflito durante as obras, neutralizando forças opostas à urbanização, especialmente a pressão dos traficantes sobre alguns moradores visando interferir no processo. ${ }^{8}$ Constituiu-se, assim, um espaço público nessas favelas, contraposto à cultura política individualista criada no seio do desenvolvimento capitalista, ali também reproduzida (Baudrillard, 1991). ${ }^{9}$

Ao fim das obras, os moradores se reconheciam como cidadãos respeitados pelo poder público e como sujeitos atuantes no processo. Mesmo que certas decisões não fossem consensuais entre eles ou entre os moradores e a prefeitura, 
para a população a intervenção era prova de reconhecimento da favela como parte da cidade. Até aquele momento, portanto, as perspectivas de integração social e alteração de condições de exclusão efetivas haviam encontrado condições propícias ao seu fortalecimento, tanto para a população quanto para outros atores sociais envolvidos. Registrava-se, porém, a preocupação com a continuidade das ações, em outra escala, para que processos desencadeados fossem consolidados. Afinal, esperava-se que esse projeto ultrapassasse a intervenção física na área e articulasse ações sociais e programas de geração de trabalho e renda para dinamizar a economia local.

\section{Problematização dos dados da pesquisa no âmbito das favelas}

O contato regularmente mantido entre o Faci e as favelas de Praia da Rosa e Sapucaia nos anos seguintes à conclusão das obras de urbanização nos colocou diante de diversas situações indicativas de que o programa não havia cumprido a expectativa inicial dos moradores quanto à superação das formas de inclusão precária dessas favelas na cidade formal. Pudemos observar a progressiva deterioração dos espaços e equipamentos públicos, da infraestrutura relativa ao esgotamento sanitário e das condições do sistema viário, a maior visibilidade da presença do narcotráfico etc. Além disso, notamos que a população local manipulava recursos materiais e simbólicos que favoreciam sua capacidade de reação. O desenvolvimento da pesquisa cujos resultados parciais apresentaremos a seguir justifica-se, então, pela necessidade de avaliarmos com maior profundidade as situações observadas, considerando que a compreensão dos processos e da correlação de forças que as movimenta ultrapassa as microestruturas e as práticas políticas locais.

Para averiguar os impactos da urbanização nos processos de inclusão/exclusão vivenciados pelos habitantes dessas favelas, consideramos importante, na etapa qualitativa da pesquisa, recuperar a visão do processo de intervenção e de seus desdobramentos tanto junto a seus moradores quanto entre os atores externos que participaram dessa experiência. Visando ampliar a abrangência de nossa análise, optamos por abordar grupos diferenciados entre os residentes entrevistados: representantes das comunidades em foco, pescadores locais, moradores mais antigos e moradores reconhecidos por sua intensa participação no processo de urbanização. Entre os atores externos às favelas, realizamos entrevistas com representantes do poder público, em especial da $\mathrm{SMH}$, com técnicos executores do projeto, com um membro do escritório de arquitetura responsável pelo projeto e com um integrante do PT que acompanhou ativamente essa experiência.

A análise das perspectivas dos diferentes atores foi facilitada pela elaboração de dois roteiros de entrevista semelhantes, utilizados para informantes internos e externos às favelas. Neles abordamos os mesmos aspectos referentes ao assunto investigado. A comparação dos depoimentos revelou uma característica significativa quanto à memória da execução do Programa Bairrinho nessas favelas: a visão dos informantes variou de acordo com o grau de comprometimento 
assumido na dinâmica dessa intervenção, e essa característica se sobrepôs à de pertencimento aos distintos grupos entrevistados. Apenas aqueles que haviam participado do processo de modo continuado foram capazes de reconstituir um relato dessa experiência com maior riqueza de detalhes e com maior profundidade de análise sobre os aspectos referentes a ela. Passemos, então, aos resultados encontrados.

\section{- Dinâmica de participação na execução do projeto e desdobramentos da intervenção}

A identificação dos atores sociais envolvidos na urbanização de Praia da Rosa e Sapucaia foi um dos aspectos analisados nessa etapa da pesquisa. Os informantes engajados de modo mais superficial no processo reconheceram apenas a prefeitura como ator social vinculado à intervenção. Um dos informantes externos mencionou também a participação do representante da Cedae. Aqueles que se envolveram de modo consistente nessa experiência reconheceram a intensa participação dos moradores como marca significativa desse processo, destacando também a atuação da prefeitura, da UFRJ (Faci), de lideranças populares filiadas ao PT e, especialmente, da então presidente da Associação de Moradores de Praia da Rosa. A participação da FAF-Rio e de integrantes do movimento popular Os Verdes foi destacada somente pelos moradores entrevistados.

As opiniões de informantes internos e externos às favelas também foram próximas quanto aos canais de participação. Em comum, apontaram: a) as reuniões sistemáticas entre a população e os demais envolvidos para definir diretrizes e resolver impasses durante a intervenção, visando à elaboração conjunta do projeto; b) a comissão de obras composta por moradores para acompanhar as obras. Os moradores citaram ainda outros canais relevantes: a) as associações de moradores; b) as assembleias comunitárias para debates e deliberações do projeto; c) o barracão para atendimentos individuais aos residentes para encaminhar situações específicas, quando não cabiam deliberações coletivas, com plantão diário de assistentes sociais e da assistência jurídica do Faci para orientar a solução de problemas apresentados pela população. Os informantes externos acrescentaram os espaços garantidos na prefeitura $(\mathrm{SMH})$ para apreciação das reivindicações populares aos demais canais mencionados.

Os entrevistados destacaram como dificuldades, lutas e resistências durante as obras: a) predomínio de interesses individuais sobre os coletivos durante os processos de negociação, especialmente em disputas de terrenos ocupados antes da intervenção e que seriam reintegrados ao espaço público; b) receio inicial dos moradores sobre a remoção e o reassentamento dos palafitados; c) oposição à abertura de trechos em vias existentes nas favelas para interligá-las e à remoção de casas situadas nesses locais, apesar da oferta de indenização ou reassentamento na favela. Os moradores acrescentaram: a) descrédito nos compromissos assumidos pelo poder público junto a segmentos mais pobres; b) dúvidas sobre implicações e desdobramentos da intervenção, após conclusão das obras; e c) 


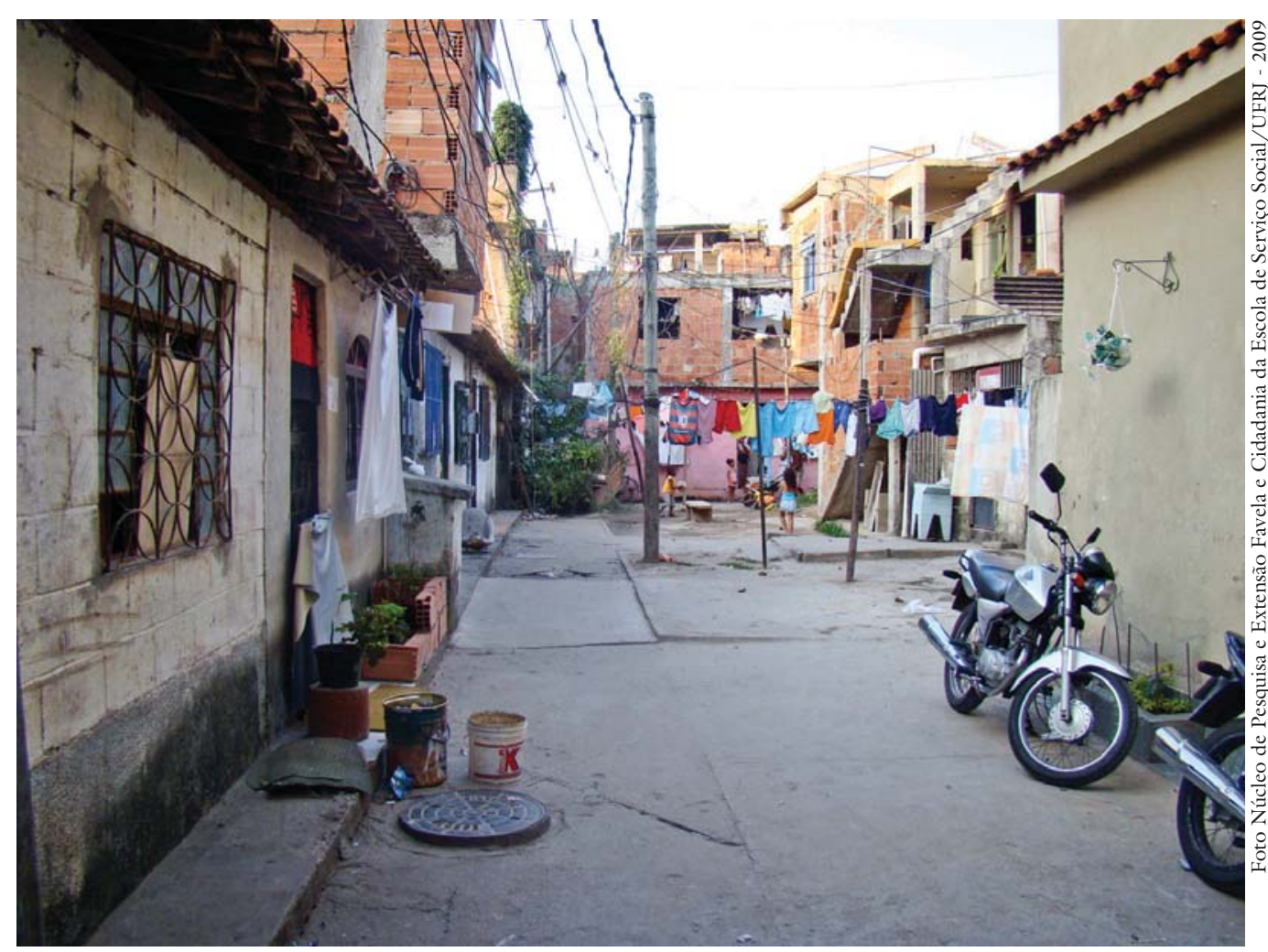

Ocupação privada na praça interna da favela de Sapucaia, na Ilba do Governador (RJ).

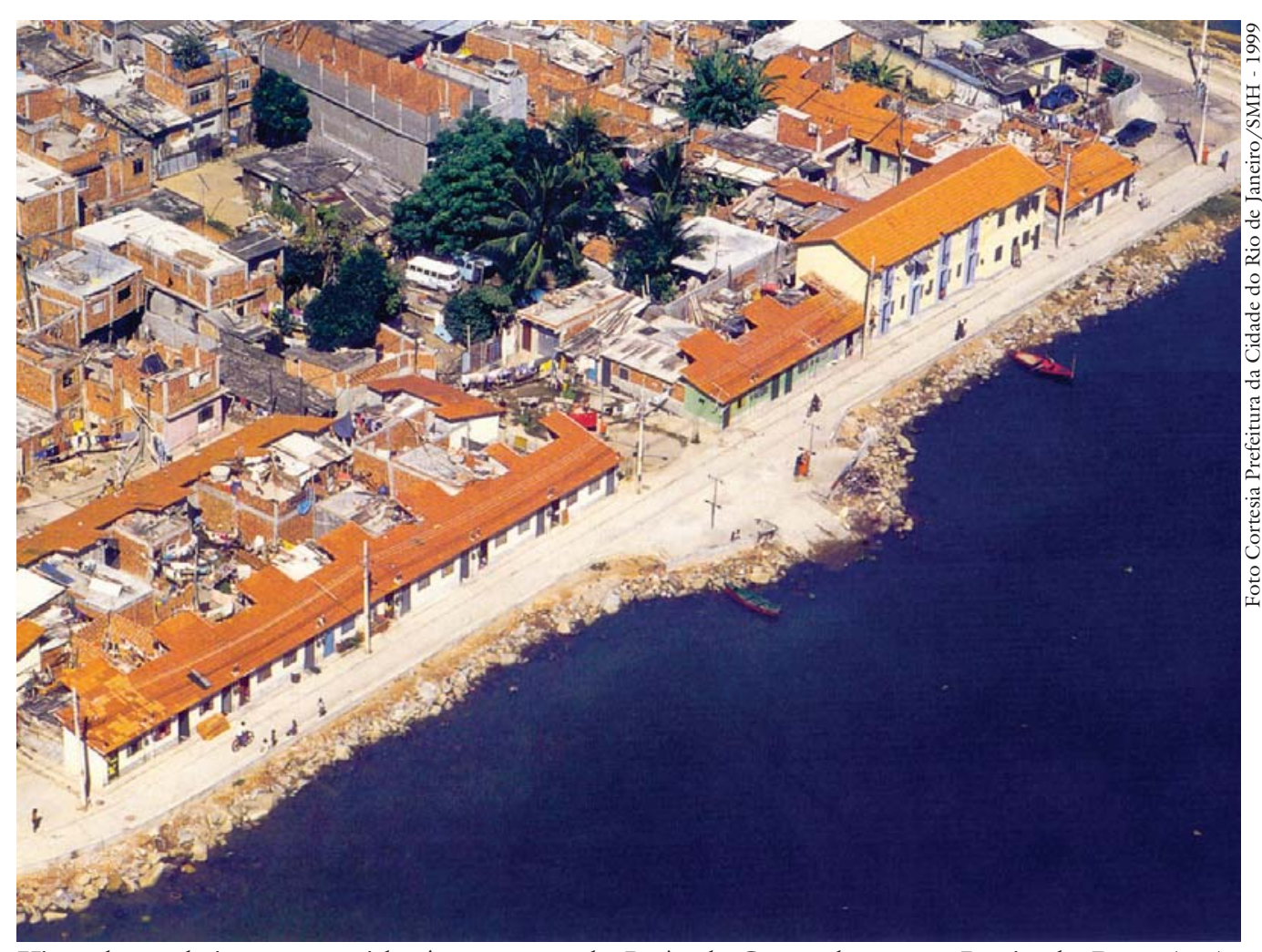

Vista dos embriões construidos às margens da Baía de Guanabara, na Praia da Rosa (RJ). 
pressão do tráfico sobre os moradores para que resistissem a alterações propostas (sobretudo abertura de vias), limitando sua livre manifestação nas assembleias. Os informantes externos às favelas também citaram: a) a não aceitação do kit construção como alternativa de reconstrução das casas, levando à construção dos embriões; b) mobilizações diversas para solucionar imprevistos encontrados ao longo da realização das obras; c) dificuldades com o aterro e seus desdobramentos.

Sobre a ação do poder público após a conclusão das obras, foi unânime a denúncia do abandono da prefeitura no que tange ao contato com a população, com críticas profundas à ausência da $\mathrm{SMH}$ e de outras instâncias públicas nas favelas, pela negligência na revisão de problemas que apareceram após as obras e na falta de manutenção das melhorias físicas feitas no espaço. Foi criticada também a falta de suporte técnico e financeiro pós-urbanização, que poderia ter sido evitado mediante a instalação e o efetivo funcionamento de um Posto de Orientação Urbanística e Social (Pouso) no local. ${ }^{10} \mathrm{O}$ aumento da força do narcotráfico nessas áreas foi outro ponto consensual na avaliação de todos os informantes.

Quase todos ignoravam haver intervenção da sociedade civil nas favelas urbanizadas. Alguns citaram: a) o trabalho da Pastoral da Criança na Igreja de São Pedro, em Praia da Rosa; b) o trabalho do Centro de Democratização da Informática (CDI); c) a distribuição de cestas básicas e vestimentas das igrejas aos fiéis; e d) a descontínua ação social do Rotary Club. Há consenso de que a urbanização não melhorou o padrão de vida dos habitantes.

Somente os informantes internos indicaram haver ação dos moradores após as obras. Julgaram relativamente frequentes as iniciativas individuais para resolver problemas de coleta de lixo, entupimento de esgoto, reparo de buracos e cuidado de praças. Observaram melhoria das casas (especialmente embriões) pelas famílias com melhores condições de vida.

\section{- Interesses atendidos,} impactos nas condições de vida dos moradores e no espaço

$\mathrm{Na}$ óptica dos entrevistados, os objetivos da prefeitura com relação à urbanização consistiam na abertura de ruas, na construção de praças e creche, na melhoria dos serviços de água e esgoto, e na execução de aterro para eliminação das palafitas. Embora considerassem que as obras atenderam a interesses gerais dos moradores, apresentaram diversas ressalvas. Os antigos palafitados criticaram a perda de espaço domiciliar antes construído. Queriam que os embriões tivessem contemplado as necessidades de cada família, criticando o modelo padrão adotado no projeto. A opção dos embriões dividiu, assim, a opinião dos moradores: alguns a apontaram como ganho da população, enquanto outros questionam a lógica de distribuição das casas e a dimensão dada a elas, gerando sentimento de injustiça diante dessa solução. Com relação à creche, os moradores reclamam que essa não absorveu toda a demanda local, apesar de ser considerada como ganho relevante para a população. Outros pleitos ficaram pendentes, como a 
construção de escola, posto de saúde etc. Em geral, os informantes afirmaram que os objetivos de melhoria da infraestrutura e das condições ambientais nas favelas e no entorno não foram plenamente efetivados. Esses foram limitados pela baixa qualidade das obras e, especialmente, pela não manutenção dessas. Ainda assim, os informantes entenderam que a infraestrutura local foi melhorada, significando um avanço ante as condições anteriores.

Sobre impactos da urbanização nas condições ambientais, a maioria dos moradores avaliou que: a) a presença da Comlurb não é suficiente para retirar o lixo na favela, e o Programa Gari Comunitário funciona precariamente no local; b) a baía continua muito suja; c) não há cuidado com as árvores ou com o mangue, exceto por iniciativas de alguns moradores; d) aumentou a criação de porcos, pelos traficantes, e de ratos. Um dos atores externos registrou a recuperação inicial do manguezal que beira as favelas, mas avaliou que ela logo regrediu por descontinuidade do trabalho de educação ambiental. ${ }^{11}$ A maioria dos atores externos destacou que essa questão não era um objetivo com estratégias claramente definidas na intervenção. Para eles, a eliminação das palafitas gerou efeito ambiental positivo, colaborando para conter o avanço de ocupação sobre a Baía de Guanabara na área limítrofe às favelas.

$\mathrm{Na}$ reorganização interna do espaço público e privado das favelas, os moradores entrevistados reconheceram a abertura das ruas e dos becos como ação positiva. No entanto, essa opinião é polêmica entre os que frequentemente associam essa nova condição ao aumento e à facilitação das incursões da polícia na favela. Para eles, a construção de praças e quadra de esporte foi negativa e desnecessária, pois não têm manutenção e são dominadas pelo tráfico. ${ }^{12}$ Alguns mencionam disputas entre traficantes e polícia pelo controle do espaço público, gerando a perda de liberdade de circulação nas favelas em razão dos confrontos armados entre esses atores sociais. Os informantes externos avaliaram positivamente as ações nas áreas públicas durante algum tempo após as obras, mas afirmaram sua deterioração pela ausência de dinâmicas favoráveis ao fortalecimento de novos pactos firmados. Concordaram com os moradores sobre a crescente privatização dos espaços públicos, destacando que o respeito aos limites entre espaço público e privado é objetivo de difícil alcance, até na cidade formal. ${ }^{13}$

O aumento do crescimento vertical nas favelas após as obras e a maior rotatividade dos residentes, em especial nos embriões, foram mencionados por certos moradores. Mas a imprecisão das informações exige uma avaliação cuidadosa sobre a permanência da população no local.

\section{- Impactos na dinâmica econômica e na dinâmica política da favela}

Segundo os entrevistados, a urbanização das favelas não gerou maiores alterações na dinâmica econômica local. Os atores externos consideram que a localização das favelas na cidade e em seu entorno tem maior peso na dinâmica econômica da área do que a intervenção física. Para os moradores, não houve aumento na oferta de serviços, nem interesse externo por esse tipo de investi- 
mento nas favelas. Apenas os habitantes abriram algum negócio (sacolão, videolocadora, loja de roupa e vendinhas), sem muito recurso ou novidade. Os residentes ainda resolvem suas principais necessidades de consumo fora da favela. Quanto aos impactos da intervenção na dinâmica politica que envolve a favela, os moradores entrevistados citaram que as favelas voltaram a ser abandonadas pelo afastamento quase absoluto do poder público após as obras. Para eles, nem as associações de moradores se fortaleceram. Os informantes de Sapucaia, em especial, denunciam a cooptação da entidade pelo narcotráfico nos anos seguintes às obras. Por algum tempo, a associação permaneceu sem representação eleita pela população, sem liderança para defender os interesses dos moradores. Recentemente elegeram nova diretoria para Associação de Moradores de Praia da Rosa e o presidente propôs unificar as comunidades numa mesma associação, obtendo tal aprovação.

Os habitantes das duas favelas destacaram também a política de segurança pública repressiva que atinge os moradores no conflito entre os traficantes e a polícia. Em Sapucaia, mais do que em Praia da Rosa, fizeram referências incisivas a esses conflitos, mais frequentes nessa favela. Na opinião deles, não sofrem apenas discriminação, mas o aprofundamento da estigmatização, mediante a criminalização dos moradores, reforçada pela mídia, o que é reconhecido também pelos atores externos. Ademais, todos concordam que houve uma desmobilização tanto das lideranças quanto dos moradores após a intervenção. ${ }^{14}$

\section{Considerações finais}

As informações qualitativas obtidas nessa fase do estudo confirmaram indícios detidos nos últimos de contato com o campo, fortalecendo a relevância de investigações quantitativas. Afinal, cremos que a compreensão das dinâmicas que ocorrem na esfera cotidiana indica pistas elucidativas para explicar a relação entre integração/exclusão social em nosso país e as mudanças na sociedade contemporânea.

Podemos afirmar que o progressivo distanciamento entre os atores centrais envolvidos no planejamento e na execução da urbanização de Praia da Rosa e Sapucaia, nos últimos anos, acarretou problemas de ordens diversas. Conforme indicam os depoimentos, esse quadro foi agravado pela negligência quase absoluta do poder público para com as necessidades da população local redimensionadas após essa intervenção. O distanciamento resultou na quase total incapacidade do poder público para avaliar os impactos dessas ações, dificultando corrigir e prevenir erros para outras intervenções que seguem os mesmos moldes. Além disso, cria sérios obstáculos ao planejamento de qualquer ação futura nas áreas em que se atuou.

Também é relevante apontar as implicações do distanciamento do poder público no enfraquecimento das entidades representativas e no fortalecimento do narcotráfico na área, com repercussões nas formas de controle e uso do espaço nessas favelas. No Rio de Janeiro, as favelas continuam crescendo sem ser 
integradas ao espaço formal. O próprio poder público reconhece que a ideologia individualista dominante em nossa sociedade, aliada à diminuição do papel social Estado nas políticas públicas, dificulta a reversão desse processo. O Programa Bairrinho tinha, no interior dessas áreas, o desafio da (re)definição de seu espaço físico, isto é, de colocar os limites entre as suas dimensões pública e privada. Entretanto, observa-se que os limites entre espaço público e privado são tênues, ora prevalecendo mecanismos que já orientavam a construção do espaço físico nessas áreas, ora acarretando retrocessos nas práticas anteriores. A problemática de integração/segregação social hoje, segundo o próprio poder público, enfrenta um novo desafio em face da correlação de forças entre a relação formal/ informal na cidade, que extrapola as situações das favelas cariocas.

Tal constatação, entretanto, na medida em que considera o domínio do espaço como fonte de poder social (Lefebvre, 1974; Santos, 1996), entende que sua produção e uso estão relacionados a mecanismos de democracia que, embora possuam autonomia relativa quanto ao seu potencial de origem, devem ser assegurados também pelo Estado (Gomes, 2002). Assim, a desmobilização dos moradores, a desestruturação das associações de moradores, bem como do espaço público construído no momento da implementação do projeto, pode ser atribuída, especialmente, aos efeitos acentuados pela ausência do poder público como mediador fundamental para a consolidação de um espaço público na área e, no desenvolver desse movimento, como instância legitimadora do sentimento de pertencimento dos moradores das favelas no conjunto da cidade. Os habitantes, portanto, continuam vivenciando situações de risco e de vulnerabilidade, nas quais se reproduzem diversas formas de exclusão historicamente observadas, cujas raízes se localizam no período anterior à urbanização.

\section{Notas}

1 Tendo em vista o desafio inerente à complexidade do assunto, será priorizado no âmbito deste estudo o debate brasileiro sobre o tema, referindo-se eventualmente a autores estrangeiros na medida em que o pensamento destes possa contribuir para melhor fundamentar as questões abordadas (Gomes et al., 2006).

2 Esse é o enfoque de Oliveira (2003) quando analisa as condições vividas pelo crescente contingente de miseráveis no Brasil. Para ele, esse segmento constitui-se, sobretudo, em uma massa de trabalhadores que, não apresentando qualificação correspondente às exigências das novas configurações do mercado de trabalho, sequer consegue manterse como parte do exército industrial de reserva, perdendo sua relevância na dinâmica produtiva.

3 A favelização é fenômeno das cidades do Terceiro Mundo. Os favelados representam $6 \%$ da população urbana dos países desenvolvidos, mas constituem $78 \%$ dos habitantes urbanos dos países periféricos (Davis, 2006).

4 Essa situação foi verificada na pesquisa desenvolvida, no período de $2005 / 2007$, denominada "La petite fabrique locale du développement urbain durable", realizada sob nossa coordenação com o recursos do governo francês. 
5 O Programa Bairrinho, em escala menor que o Favela-Bairro, visa integrar as favelas à cidade por melhorias em infraestrutura urbana, serviços e equipamentos públicos, em articulação com outras políticas sociais.

6 No Brasil, tal intervenção foi referência aos programas Baixada Viva (Rio de Janeiro, 1997) e Urbanização de Favelas (São Paulo, 1998), além do Programa Nacional de Urbanização, Habitar Brasil (1998). Programas foram criados na Argentina (Programa Nacional de Urbanização de Bairros, 1996), Equador (Programa de Suporte ao Setor Habitacional, 1997), Bolívia (Programa de Reforma do Setor Habitacional, 1998) e Uruguai (Desenvolvimento Municipal, 1997, e Integração de Assentamentos Informais, 1999) (Brakarz \& Engel, 2004).

7 A Região Ilha do Governador cobre uma área de 4.081 hectares. Nela residem 211.469 habitantes, segundo o Censo 2000. É formada por 15 bairros: Bancários, Cacuia, Cidade Universitária, Cocotá, Freguesia, Galeão, Jardim Carioca, Jardim Guanabara, Moneró, Pitangueiras, Portuguesa, Praia da Bandeira, Ribeira, Tauá e Zumbi.

8 A interferência significativa do tráfico na favela, no que se refere à luta local pela urbanização, já fora registrada durante a mobilização ocorrida em 1986. Para maiores detalhes, ver Gomes \& Bastos (1994).

9 A cultura individualista mostrou seus efeitos na organização da vida coletiva, via atomização do espaço social, dificuldade de mobilização e motivação política dos moradores, engajados na luta por sobrevivência imediata.

10 A orientação oficial da prefeitura ao término das obras nessas favelas foi de que seus moradores se dirigissem ao Pouso situado em Parque Royal, favela relativamente próxima a essas, em caso de necessitarem de orientação para expansão ou melhorias das construções. No entanto, o posto indicado não conseguiu absorver a demanda a ele encaminhada tanto por falta de recursos quanto por dificuldades de aproximação com essas duas favelas.

11 De fato, as parcas iniciativas tomadas nessa direção contaram com a mobilização dos moradores em razão da tradição pesqueira na área e do resgate dessa característica nas reflexões e reuniões com a população das favelas.

12 A ampliação do espaço público jamais se colocou como prioridade para os moradores, que anteviam as reais limitações para a sua consolidação. Para eles, esses espaços poderiam ter sido usados para novas moradias.

13 Informante vinculado à SMH sinalizou que o Estado tem perdido espaço no controle dos pactos sociais e na orientação das relações no espaço urbano, prevalecendo mecanismos considerados ilegítimos pelo poder público.

14 Alguns dos impactos da urbanização nessas áreas, hoje concretizados, já haviam sido antevistos e ponderados por Gomes \& Bastos (1994), Gomes (2002) e por Fernandes (2006).

\section{Referências bibliográficas}

BAUDRILLARD, J. (Org.) Citoyenneté et urbanite. Paris: Sprit, 1991.

BRAKARZ, J.; ENGEL, W. A. Favela-Bairro: scaled-up urban development in Brazil. Washington, D.C.: Inter-American Development Bank, 2004. 
BUARQUE, C. O colapso da modernidade brasileira e uma proposta alternativa. Rio de Janeiro: Paz e Terra, 1991.

O que é apartação. São Paulo: Brasiliense, 1993.

CARDOSO, A. L. (Org.) Habitação social nas metrópoles brasileiras: uma avaliação das políticas habitacionais em Belém, Belo Horizonte, Porto Alegre, Recife, Rio de Janeiro e São Paulo no final do século XX. Porto Alegre: Antac, 2007. (Coleção Habitare).

CARDOSO, F. H.; FALLETO, E. Dependência e desenvolvimento na América Latina. Rio de Janeiro: Zahar, 1970.

CONDE, L. P.; MAGALHÃES, S. Favela-Bairro: uma outra história da cidade do Rio de Janeiro. Rio de Janeiro: ViverCidades, 2004.

DAVIS, M. Planeta Favela. São Paulo: Boitempo, 2006.

ELIAS, N.; SCOTSON, J. L. Os estabelecidos e os outsiders: sociologia das relações de poder a partir de uma pequena comunidade. Rio de Janeiro: Zahar, 2000.

FERNANDES, L. L. Política urbana e produção do espaço em favelas do Rio de Janeiro: a busca pelo direito à cidade. Rio de Janeiro, 2006. Tese (Doutorado) - Instituto de Pesquisa e Planejamento Urbano e Regional, Universidade Federal do Rio de Janeiro.

Favelas: desafios à articulação entre política urbana e política habitacional na cidade do Rio de Janeiro, no início do século XXI. In: SEMANA IPPUR, 10, 2003, Rio de Janeiro. Anais... Rio de Janeiro: Ippur, 2003. v.1.

GOMES, M. F. C. M. Cidadania e espaço público numa experiência de política de urbanização de favelas. In: RAUTA RAMOS, M. H. (Org.) Metamorfoses sociais e políticas urbanas. Rio de Janeiro: DP\&A, 2002.

Política de habitação e sustentabilidade urbana. In: GOMES, M. F. C. M.; PELEgrino, A. I. C. (Org.) Politica de habitação e trabalho social. Rio de Janeiro: DP\&A, 2006.

GOMES, M. F. C. M.; BASTOS, M. D. F.. Sobre o caráter político das Associações de Moradores em Favelas. Revista Serviço Social e Sociedade, ano XV, n.46, dez. 1994.

GOMES, M. F. C. M.; FERNANDES, L. L. A Mercantilização da cidade e a questão do desenvolvimento local. O Social em Questão, v.18, p.103-21, 2007.

GOMES, M. F. C. M. et al. Desigualdade e exclusão nas metrópoles brasileiras: alternativas para seu enfrentamento nas favelas do Rio de Janeiro. Rio de Janeiro: HP Comunicações \& Arco-Íris, 2006.

GUIMARÃES, A. A. et al. A propósito do debate sobre exclusão social: aportes teóricos, escala local e indicadores sociais. In: ENCONTRO NACIONAL DE GEÓGRAFOS, 12, 2002, João Pessoa: AGB, jul. 2002.

LEFEBVRE, H. La production de l'espace. Paris: Anthropos, 1974.

LAPLANTINE, F.; PORDEUS JÚNIOR, I. A. (Org.) Usages sociaux de la mémoire et l'imaginaire au Brésil et en France. Lyon: Presses Universitaires de Lyon, 2001.

MARTINS, J. S. Exclusão e a nova desigualdade. São Paulo: Paulus, 1997.

OLIVEIRA, F. M. C. A economia brasileira: critica à razão dualista. Revista Novos Estudos Cebrap, São Paulo, v.2, p.3-82, 1972. 
OLIVEIRA, F. M. C. Crítica à razão dualista. O ornitorrinco. São Paulo: Boitempo Editorial, 2003.

OLIVEIRA, L. Os excluídos existem? Notas sobre a elaboração de um novo conceito. Revista Brasileira de Ciências Sociais, São Paulo, Anpocs, ano 12, n.33, 1997.

PIQUET, R. (Org.) Rio de Janeiro: perfis de uma metrópole em mutação. Rio de Janeiro: Ippur, UFRJ, 2000.

PLANO ESTRATÉGICO da cidade do Rio de Janeiro. Rio Sempre Rio. Rio de Janeiro: PCRJ, ACRJ, Firjan, 1996.

As cidades da cidade. Rio de Janeiro: PCRJ, 2004.

PREFEITURA DA CIDADE do Rio de Janeiro. Cidade Inteira: a política habitacional da cidade do Rio de Janeiro. Rio de Janeiro: PCRJ, SMH, 1999.

Plano estratégico da cidade do Rio de Janeiro. Rio Estudos, n.78, nov. 2002. Coleção Estudos da Cidade.

RANDOLPH, R. Determinações estratégicas e potencialidades de transformação do Programa Favela-Bairro. GEOgraphia: Revista do Programa de Pós-graduação em Geografia da UFF, Rio de Janeiro, ano III, n.5, jul./dez. 2001.

Arenas políticas e agenciamentos governamentais: uma discussão de novos formatos a partir da experiência do Programa Favela Bairro e do Plano Estratégico da cidade do Rio de Janeiro. In: RIBEIRO, A. C. T. (Org.) O rosto urbano da América Latina. Ciudad de Buenos Aires: Clacso, 2004. p.273-300. (Coleccion Grupos de Trabajo del Consejo Latinoamericano de Ciencias Sociales - Clacso).

SANTOS, M. A natureza do espaço. São Paulo: Hucitec. 1996.

VERAS, M. P. B. Notas ainda preliminares sobre exclusão social: um problema brasileiro de 500 anos. In: VERAS, M. P. B. et al. (Ed.) Por uma sociologia da exclusão social. O debate com Serge Paugan. São Paulo: Educ, 1999.

WACQUANT, L. Da América como avesso da utopia. In: LINS, D. (Org.) Cultura e subjetividade. Saberes nômades. São Paulo: Papirus, 2000.

XIBERRAS, M. As teorias da exclusão: para a construção de um imaginário do desvio. Lisboa: Instituto Piaget, 1993.

RESUMO - O trabalho apresenta resultados qualitativos do follow-up referente à urbanização das favelas Praia da Rosa e Sapucaia, realizada pela Prefeitura Municipal da Cidade do Rio de Janeiro, entre 1996 e 1998. A primeira etapa deste estudo teve por objetivo identificar a visão dos diferentes atores sociais envolvidos nessa intervenção sob os efeitos da política destinada às favelas, no que se refere às condições de inclusão/exclusão social dos moradores desses locais. Na etapa seguinte desta pesquisa, serão coletadas informações de natureza quantitativa, de modo a ampliar e aprofundar a análise dos processos identificados no desdobramento da urbanização dessas favelas.

PALAVRAS-CHAVE: Favelas, Urbanização, Exclusão social.

ABSTRACT - This follow-up study presents the previous qualitative results of the urbanization of the slums of Praia da Rosa and Sapucaia, implemented by the Municipality of 
Rio de Janeiro, through the Bairrinho Program, in 1996-1998. It is a theoretical and empiric study which will be completed by the update of the Census made before this intervention in both slums. We aim to verify the contribution of this policy in order to modify the condition of social inclusion/exclusion of inhabitants in these areas. Different processes related to the phenomenon of urban inclusion/exclusion have been considered on this research.

KErWORDs: Slums, Urbanization, Social exclusion.

Maria de Fátima Cabral Marques Gomes é doutora em Serviço Social (PUC-SP), professora titular da Escola de Serviço Social (UFRJ), pesquisadora do CNPq e coordenadora do Núcleo de Pesquisa e Extensão Favela e Cidadania (Faci/ESS/UFRJ).

@ - fcmgomes@gmail.com

Lenise Lima Fernandes é doutora em Planejamento Urbano e Regional (Ippur-UFRJ), professora adjunta da Escola de Serviço Social (UFRJ), vice-coordenadora do Núcleo de Pesquisa e Extensão Favela e Cidadania (Faci/ESS/UFRJ).

@ - leniself@uol.com.br

Recebido em 18.5.2009 e aceito em 2.6.2009. 